\title{
PROGRAMA DE VIVIENDAS EXPERIMENTALES EN MÓSTOLES, COMUNIDAD DE MADRID. ESPAÑA
}

\section{(EXPERIMENTAL HOUSING PROGRAMME IN MOSTOLES, COMMUNITY OF MADRID, SPAIN)}

\author{
Manuel Abad Carrascosa, Arquitecto \\ Carlos Gómez Agustí, Arquitecto \\ Guillermo Yáñez, Arquitecto
}

193-22

Fecha de recepción: 5-X-89

\section{RESUMEN}

Esta actuación consta de un total de 102 viviendas. Se encuentran localizadas en uno de los polígonos del Plan General de Urbanismo del Ayuntamiento de Móstoles (Población del extrarradio de Madrid). Se plantea el estudio y desarrollo, por separado, de tres prototipos diferentes de vivienda con el fin de poder estudiar los resultados experimentales de cada uno:

- Viviendas progresivas.

- Viviendas con energía solar pasiva.

- Viviendas construidas a base de un sistema especial en serie.

Los tres plantean el ahorro económico como fin común, pero desde distintas bases de partida: la inversión inicial; el ahorro energético, y el sistema constructivo.

El conjunto se encuentra a punto de ser entregado a sus usuarios. Lamentamos lo incompleto de la información debido a la falta de sus resultados más importantes: los derivados de su uso y desarrollo; sociales, económicos, culturales, etcétera.

\section{SUMMARY}

This programme consists of a total of 102 houses. They are situated in one of the housing estates in the General Urbanization Plan of the Móstoles Town Council (Town on outskirts of Madrid). The development of the prototypes of three different types of housing is to be studied with the aim of studying the experimental results of each one:

\section{- Progressive housing.}

- Housing with passive solar energy.

- Housing constructed on a basis of a special system in series.

The three have the common aim of achieving finanical saving, but by different means: initial investment, saving in energy expenditure, the constructive system.

The group of houses is about to be delivered into the hands of its users. We regret the incompleteness of the information due to the lack of the most important results; the derivatives of its use and development, and information of a social, economic, cultural, etc., character.

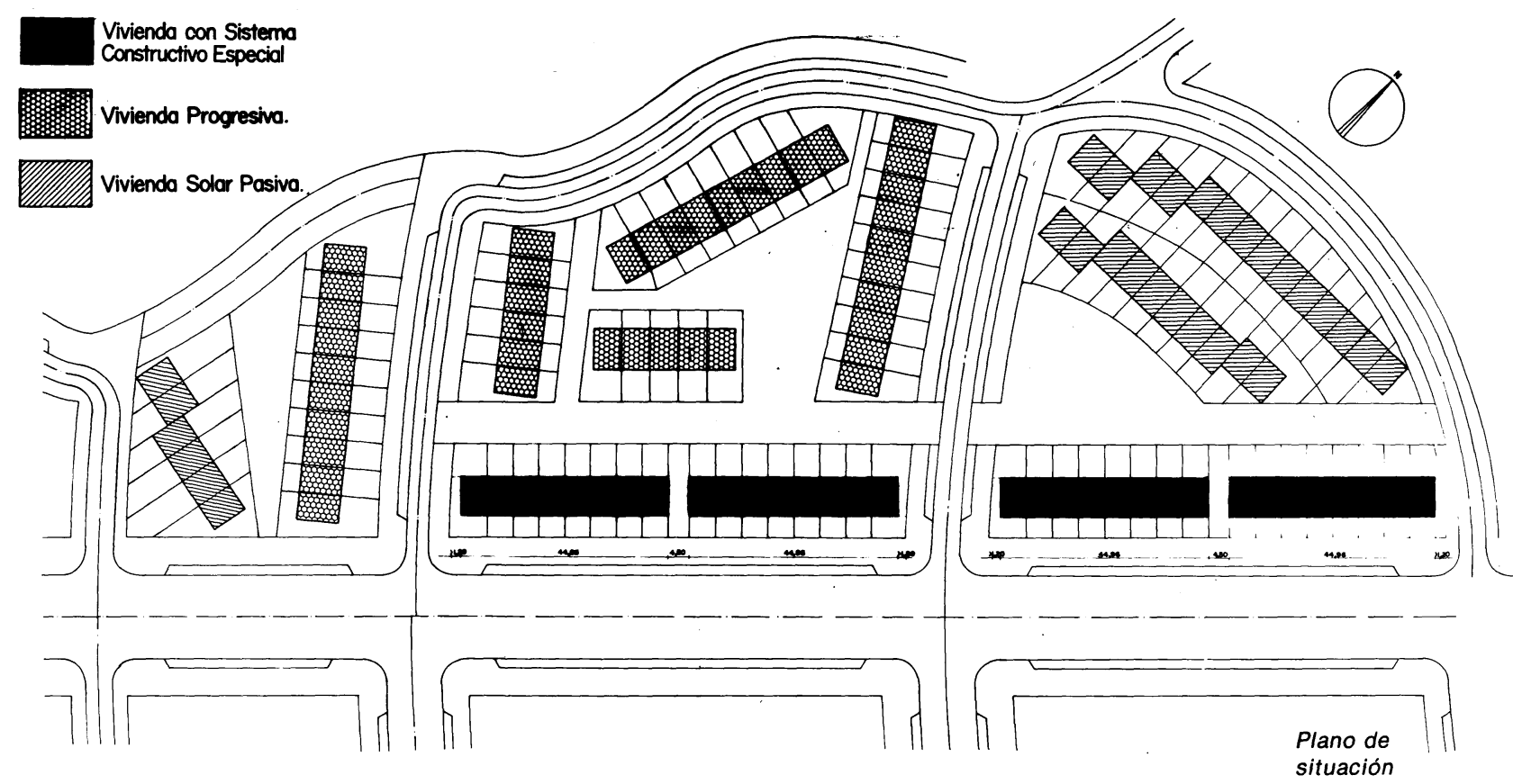



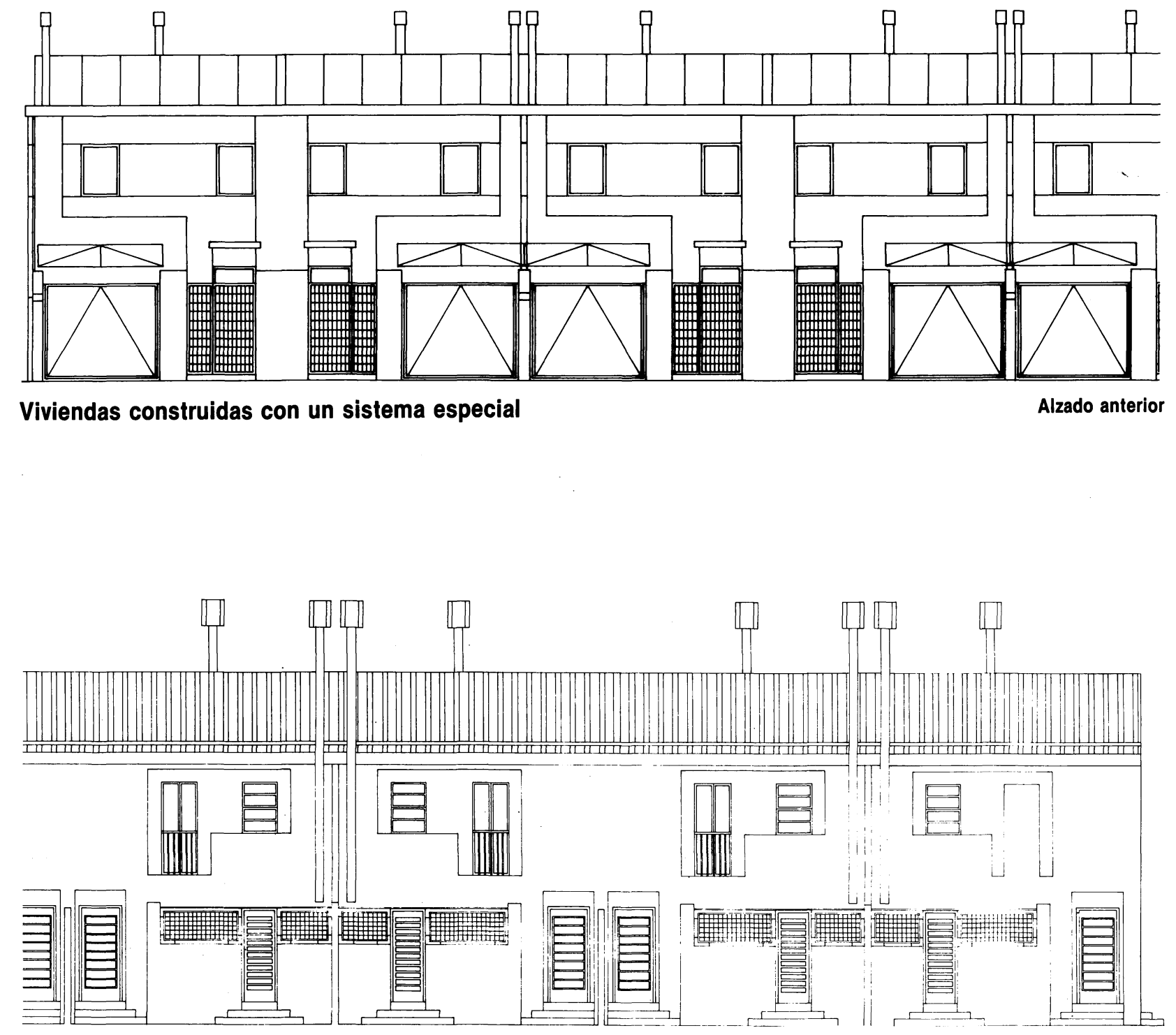

Viviendas progresivas

Alzado anterior

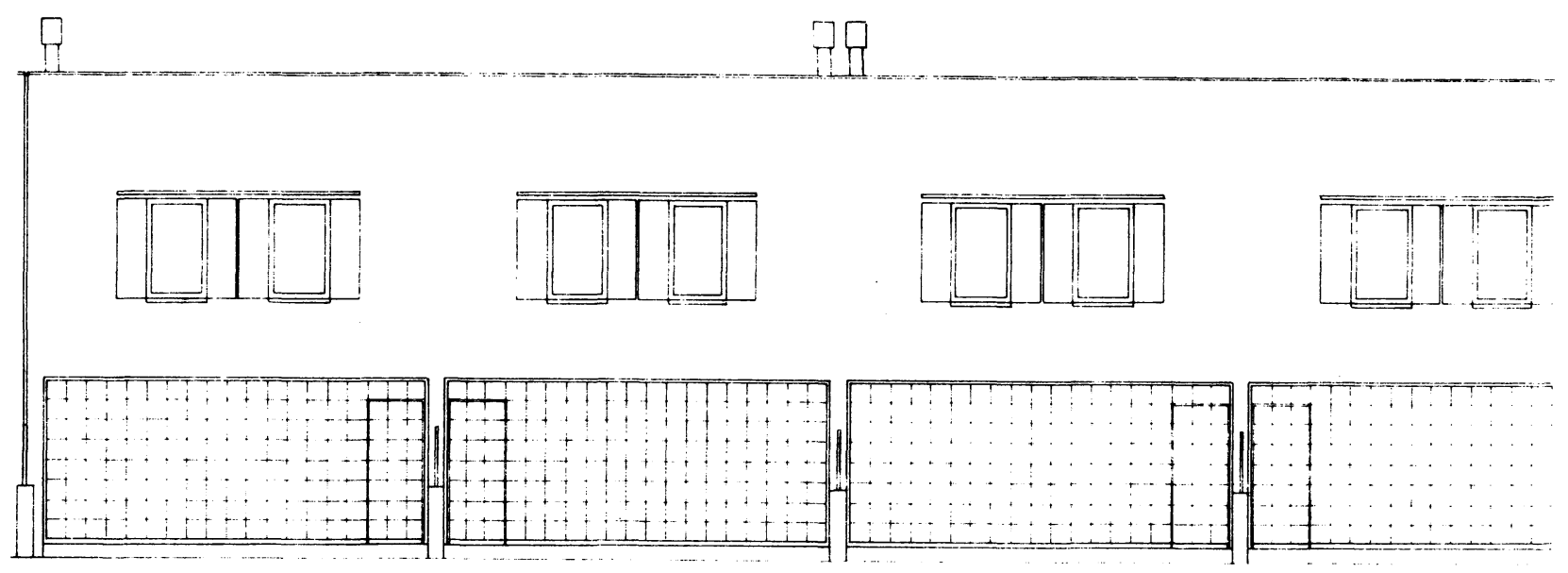

Viviendas con energía solar pasiva

Alzado anterior (sur)

(C) Consejo Superior de Investigaciones Científicas Licencia Creative Commons 3.0 España (by-nc) 


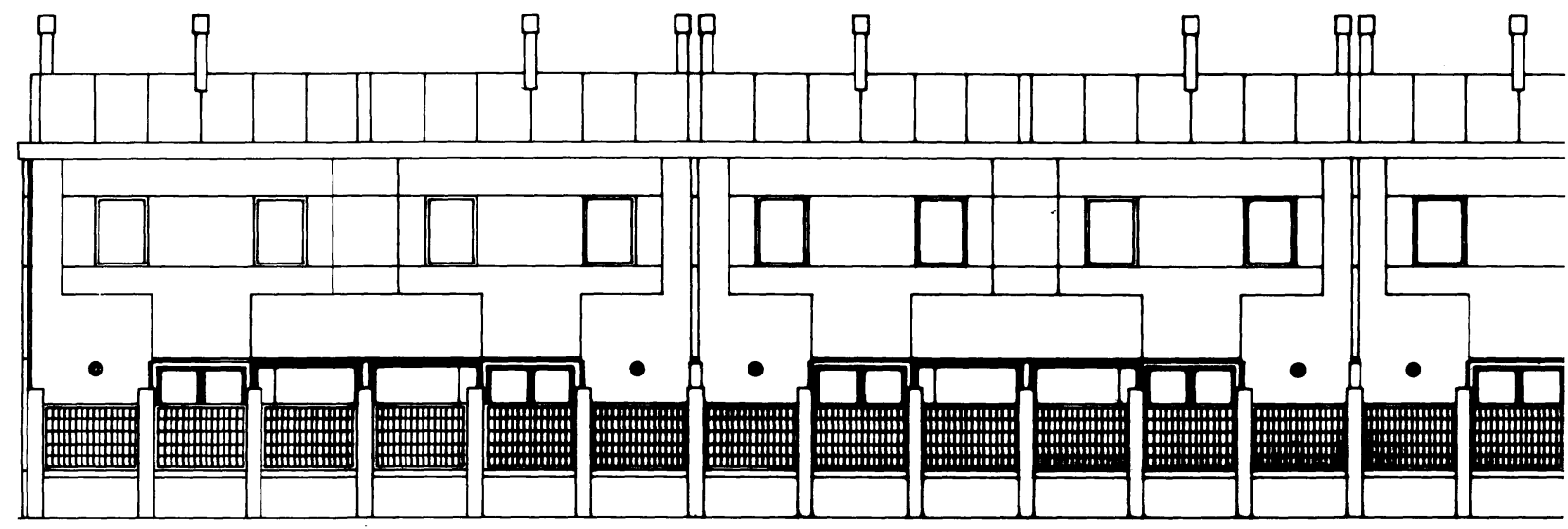

Viviendas construidas con un sistema especial

Alzado posterior

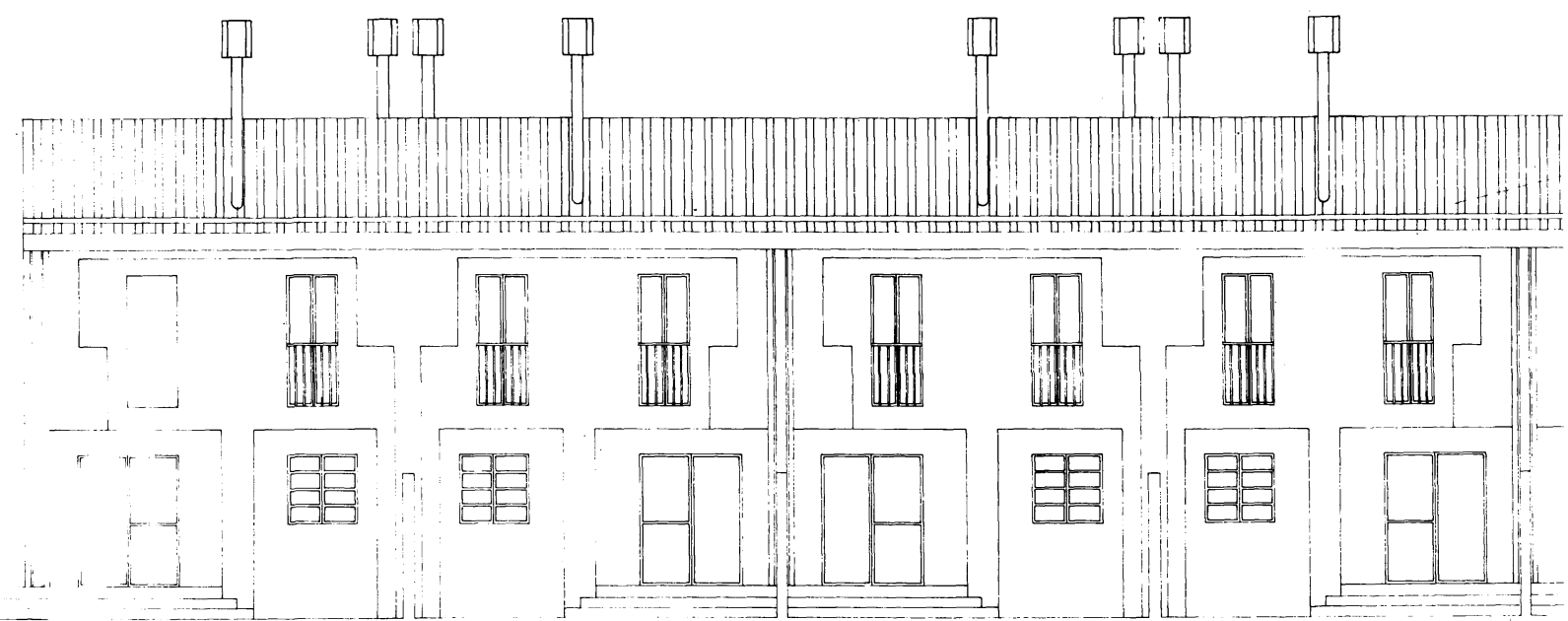

Viviendas progresivas

Alzado posterior

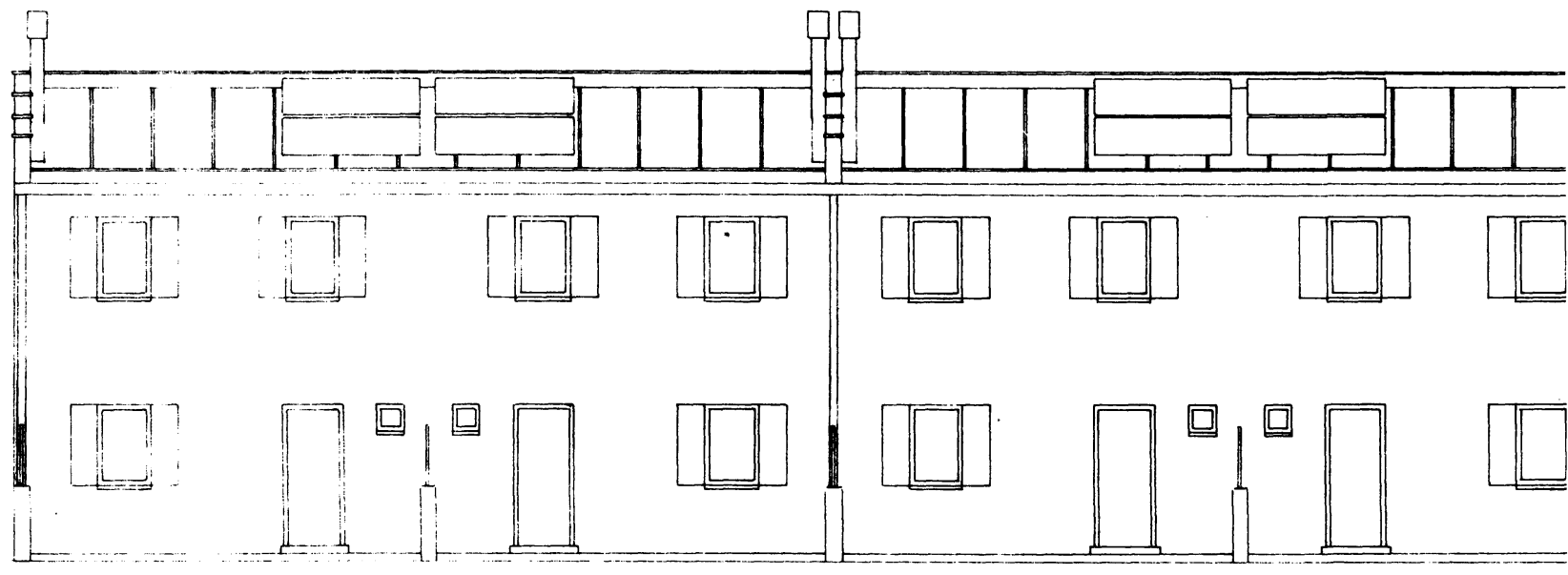

Viviendas con energía solar pasiva

Alzado posterior (norte) 


\section{PREÁMBULO}

En 1985 la Dirección General de Arquitectura de la Comunidad de Madrid encarga la realización de la presente actuación, dentro de su programa de vivienda social.

Ésta consta de un total de 102 viviendas. Se encuentran localizadas en uno de los polígonos del Plan General de Urbanismo del Ayuntamiento de Móstoles (Población del extrarradio de Madrid). Por tanto, se encuentran sujetas a la ordenanza de dicho Plan General y a la correspondiente a Viviendas de Protección Oficial (V.P.O.).

La Ordenanza del polígono permite un volumen de edificación para "viviendas en hilera" de dos alturas. Por otra parte, el programa de la vivienda debe cumplir los requisitos de las Normas V.P.O.: 3 dormitorios, 1 baño, cocina y estar en $90 \mathrm{~m}^{2}$, con los correspondientes (\%) para minusválidos y el presupuesto económico ajus. tado al módulo oficial fijado en ptas $/ \mathrm{m}^{2}$ construidos.

Con toda esta normativa oficial como premisa de partida: Iugái, ordenanza, programa y presupuesto se plantea, desde la Dirección General, el estudio y desarroIlo por separado de tres prototipos diferentes de vivienda para dicho lugar. Los planteamientos y objetivos son distintos en cada caso, con el fin de poder estudiar por separado los resultados experimentales de cada uno. Se proponen asi los siguientes prototipos:

- 40 viviendas progresivas;

- 30 viviendas con energía solar pasiva;

- 32 viviendas construidas a base de un sistema especial en serie.

Desde el punto de vista urbano se organizan los tres tipos de forma que configuren dos patios interiores de "manzana", acoplándose a las condiciones urbanisticas y del programa.

(C) Consejo Superior de Investigaciones Científicas Licencia Creative Commons 3.0 España (by-nc)
Los tres plantean, desde el punto de vista experimental, el ahorro económico como fin común, pero desde distintas bases de partida:

- Las viviendas progresivas desde el aspecto de la inversión inicial: financiación, amortización,...

- Las viviendas solares pasivas desde el ahorro energético.

- Y las viviendas con sistema constructivo especial desde el rendimiento del material y la mano de obra.

El proyecto se realizó en 1985, y en este mismo año se redactó. Se comenzaron las obras en 1987, las cuales fueron interrumpidas por motivos político-administrativos, reanudándose en 1988. En la actualidad el conjunto se encuentra a punto de ser terminado y en condiciones de entrega (a falta de acondicionamiento urbano, fundamentalmente).

En un país como el nuestro, donde la construcción de la vivienda y su necesidad crecen inexorablemente, y dentro de un Mercado Empresarial como el Europeo altamente especializado, son pocos los ejemplos e iniciativas oficiales de este carácter con los que podemos contar. Es este carácter de excepcionalidad de la presente actuación, el que nos anima a su publicación. Ofrecemos sólo el resultado de su ejecución material, lamentando por unas razones $u$ otras lo incompleto de la información, dada la falta de sus resultados más im. portantes: los derivados de su uso y desarrollo; sociales, económicos, culturales,... Sirva, no obstante, la situación actual que reflejan como un importante sintoma, a tener en cuenta, a la hora de efectuar su análisis. 